absolutely resembled his parent, the number of children who deviated $x$ would vary as $e^{-\frac{x^{3}}{f^{2}}} \times e^{-\frac{x^{2}}{c_{3}^{2}}}$, or as $e^{-x^{2}\left\{\frac{I}{f^{2}}+\frac{x}{c_{2}^{2}}\right\}}$. Hence the deviations of the children in their amount and frequency would conform to the law, and the modulus of the population of children in the supposed case of absolute resemblance to their parents, which we will write $c_{3}$, is such that-

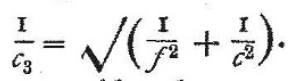

We may, however, consider the parents to be multiplied

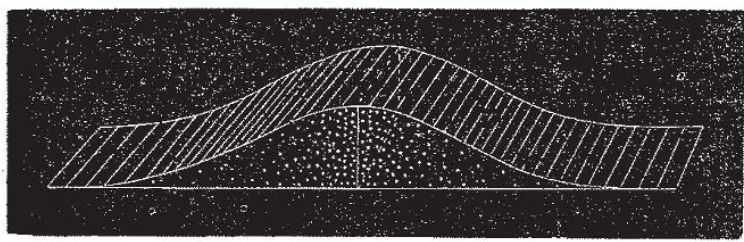

Fig. 6.

and the productivity of each of them to be unitorm. It is more convenient than the converse supposition and it comes to the same thing. So we will suppose the reverted parentages to be more numerous but equally prolific, in which case their modulus will be $c_{3}$, as above.

4. Family variability was shown by experiment to follow the law of deviation, its modulus, which we will write $v$, being the same for all classes. Therefore the amount of deviation of any one of the offspring from the mean of his race is due to the combination of two influences, the deviation of his "reverted" parentage and his own family variability; both of which follow the law of deviation. This is obviously an instance of the wellknown law of the "sum of two fallible measures" (Air), "Theory of Errors," \$43). Therefore the modulus of the population in the present stage, which we will write $c_{4}$, is equal to $v\left(v^{2}+c_{3}^{2}\right)$.

5. Natural selection follows, as has been explained, the same general law as productiveness. Let its modulus be written $s$; then the percentage of survivals among children, who deviate $x$ from the mean, varies as $-\frac{x^{2}}{3^{2}}$

its effect will be to leave the population still in conformity

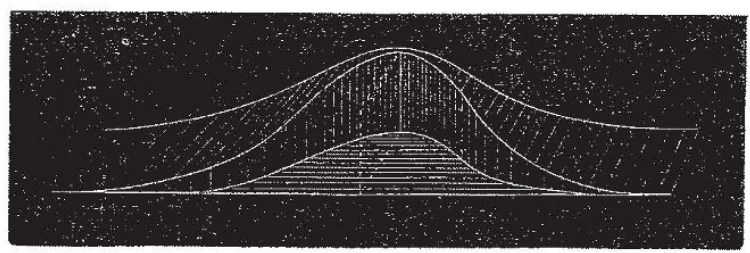

Fig. 7.

with the law of deviation, but with an altered modulus, which we will write $c_{5}$, and

$$
\frac{\mathbf{I}}{c_{5}}=\sqrt{\left(\frac{\mathrm{I}}{s^{2}}+\frac{\mathrm{I}}{c_{4}^{2}}\right) .}
$$

Putting these together we have, starting with the original population having a modulus $=c_{0}:-$

$$
\begin{aligned}
& \text { 1. } c_{1}=\frac{1}{\sqrt{2}} \cdot c_{0 .} \\
& \text { 2. } c_{2}=r c_{1} . \\
& \text { 3. } c_{3}=\sqrt{ }\left\{\frac{f^{2} c_{2}^{2}}{f^{2}+c_{2}^{2}}\right\} . \\
& \text { 4. } c_{4}=\mathbb{V}\left\{v^{2}+c_{3}^{2}\right\} .
\end{aligned}
$$

$$
\text { 5. } c_{5}=\sqrt{ }\left\{\frac{s^{2} c_{4}^{2}}{s^{2}+c_{4}^{2}}\right\} \text {. }
$$

And lastly, as the condition of maintenance of statistical resemblance in consecutive generations :-

6. $c_{5}=c_{0}$.

Hence, given the coefficient $r$ and the moduli $v, f, s$, the value of $c_{0}$ (or $c_{5}$ ) can be easily calculated.

In the case of simple descent, which was the one first

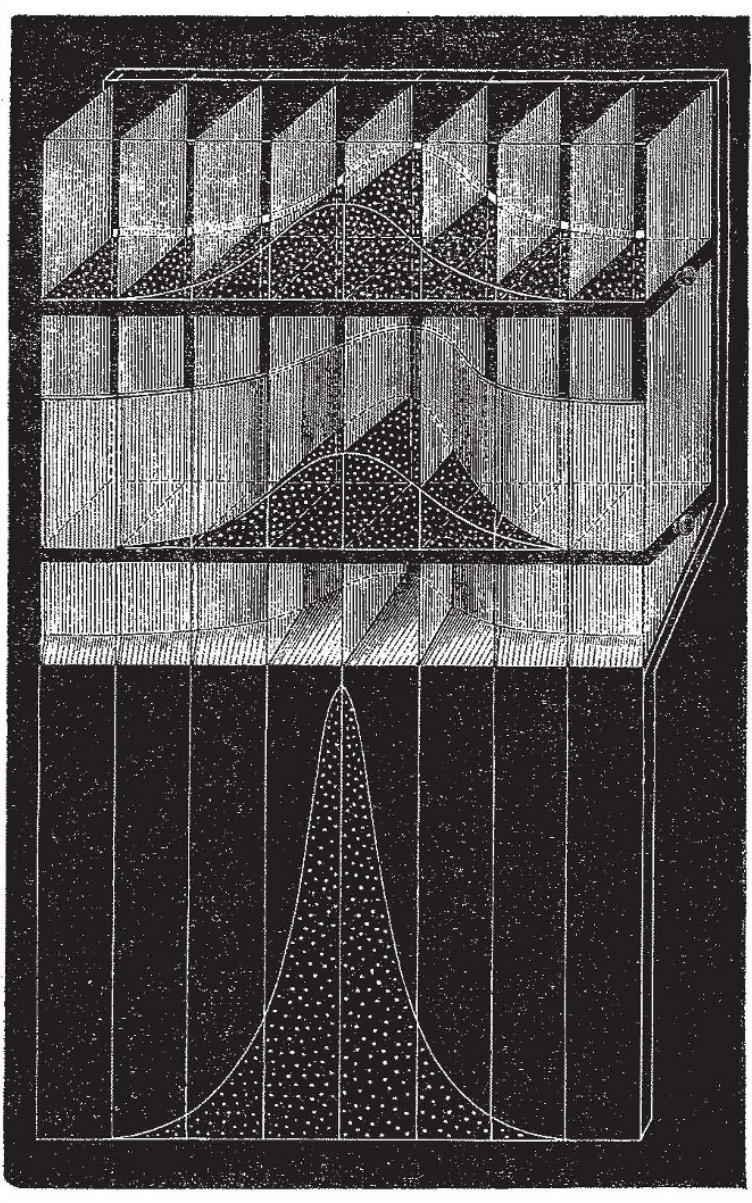

FIG. 8.

considered, we have nothing to do with $c_{0}$, but begin from $c_{1}$. Again, as both fertility and natural selection are in this case unirorm, the values of $f$ and $s$ are infinite. Consequently our equations are reduced to-

whence

$$
\begin{gathered}
c_{2}=r c_{1} ; c_{4}=\sqrt{ }\left\{v^{2}+c_{2}^{2}\right\} ; c_{4}=c_{1}, \\
c_{1}^{2}=\frac{v^{3}}{x-r^{2}}
\end{gathered}
$$

\section{CARL FRIEDRICH GAUSS}

BORN APRIL 30, 1777, DIED FEBRUARY 23, $1855^{3}$

T) E MORGAN in his "Budget of Paradoxes" (p. 187), tells the following story :-The late Francis Baily wrote a singular book, "Account of the Rev. John Flamsteed, the first Astronomer-Royal:" it was published by the Arimiralty for distribution, and the author drew up the distribution list.

I We adopt the date given by the Baron Sartorius von Waltershausen in his "Gauss. Zum Gedächtniss," Leipzig, 1856 . Encyclopedists and other authoraties are pretty equally divided between this date and April 23. All the English Cyclopadias we have consulted, with the exception of Chambers's (r874), give April 23. We may also mention that on the list of students at the Collegium Carolinum the name is Johann Friedrich Karl Gauss. We have followed Gauss himself in our heading. 
Certain rumours led to a run upon the Adniralty for copies. "The Lords were in a difficulty ; but on looking at the list they saw names, as they thought, which were so obscure, that they had a right to assume Mr. Baily had included persons who had no claim to such a compliment as presentation from the Admiralty. The secretary requested Mr. Baily to call upon him. 'Mr. Baily, my Lords are inclined to think that some of the persons in this list are perhaps not of that note which would justify their lordships in presenting this work.' 'To whom does your observation apply, Mr. Secretary.' 'Well, now let us examine the list; let me see; now-now-now-come !-here's Gauss -who's Gauss?' 'Gauss, Mr. Secretary, is the oldest mathematician now living, and is generally thought to be the greatest.'" Their Lordships ultimately expressed themselves perfectly satisfied with the list. Who then was Gauss? He was the son of a bricklayer at Brunswick, and it was the wish of his father that the boy should be a bricklayer too. The lad, however, was another Pascal, ${ }^{1}$ and early showed a marvellous aptitude for calculation; indeed he might be said to have "lisped in numbers," for he used jokingly to say that he could reckon before he could talk. When scarcely three years old he pointed out the inaccuracy of an account, "Vater, die Rechnung ist falsch, es macht so viel," and the boy was right. At the public school of Bittner he soon attracted the attention of Bartels, subsequently Professor of Mathematics at Dorpat, and father-in.law of Struve, by whom he was brought under the notice of Charles William, the reigning Duke of Brunswick. The Duke became Gauss's good friend, and sent him in $\mathrm{r}_{792}{ }^{2}$ to the Collegium Carolinum, much against the father's wish. Having nothing more to learn from the pro essors here, he went in $1795^{3}$ to Göttingen, as yet undecided whether to pursue philology or matbematics. Kaestner was at this time mathematical professor, of whom Gauss said: " $\mathrm{He}$ was the first of geometers among poets and first of poets among geometers."

Here, too, he was independent of his teachers, and having made several of his greatest discoveries in analysis (the Higher Arithmetic especially became his favourite study, and he called it a divine science, "Mathematics, the Queen of the Sciences, and Arithmetic, the Queen of Mathematics" ${ }^{4}$ ), henceforth he made mathematics the main study of his life.

Having finished his college course, he returned to Brunswick, and in I 798 repaired for a short time to Helmstadt to consult the library there. Again the next year we find him at Helm. stadt, and he is now able to improve his acquaintance with Pfaff, having had only an hour or two of intercourse with him in the previous year, and the two mathematicians were much together, the probability being that Gauss communicated more than he received. ${ }^{5}$

In 1807 , whilst a private teacher at Brunswick, the Emperor of Russia offered him a chair at the Academy of St. Petersburg, but by the advice of Olbers he declined the appointment. ${ }^{6}$ On July 9 in this year he was appointed the first director of the new Göttingen Observatory and Professor of Astronomy in the University. His life henceforth was spent at Göttingen, in the midst of continuous work ; in other respects it was quite unevent. ful. From the year 1828, when he was invited to Berlin by Humboldt to attend a meeting of natural philosophers in that city, he never left his university until 1854 , in which year railway communication was opened up between Hanover and

\$ cf. Prof. H. J. S. Smith's Presidential Address, Proceedings of London Mathematical Society, vol. viii p. I8, and Larrouse. At the age of ten he was acquainted with the Binomial Theorem and the theory of intinite series,

"Gacquainted with the Binomial Theorem and the theory of inunite series,
2 "Gauss. Zum Gedä́chtniss," p. x5. Roy. Ast. Soc. Monthly Votices, vol. xvi. pp. 80-83. Larrouse, "Grande Dictionnaire," Paris, 1872, gives

erroneously 1789 . 3 Latrouse and Michaud's "Biographie Universelle," Pa
give this date r794; see also Roy. Ast Soc. Monthly Notices.

4 "Gauss. Z. Ged.," pp. 79, 86.

5 Roy. Ast. Soc. Notices point out that the idea that Gauss studied under Pfaff is an erroneous one This error occurs in the "Encyclopædia Brit.," 1856 (8th edition). Laplace, when asked who was the greatest mathematician in Germany, replied, Pfaff; his interrogator said he should have thought Gauss was. "Oh," replied Laplace, "Pfaff est bien le plus grand mathématicien de l'Allemagne, mais Gauss est le plus grand mathématicien de Europe." The statement that Gauss graduated at Helmstadt in 1799 (Proceedings of Roy. Soc., vol. vii. p. 598) is erroneous"; see "Gauss. Z.
Ged.," p. 22. The degree was conferred upon him in absentiâ. No information upon this point is given either in Poggendorff, "Biog. Lit Handwörterbuch," Leipzig, 1863, or in the Gottingische gelchrte Anzeigen (3rd vol. for 1855 )

Olbers, in a letter to Heeren, states that Gauss had a marked objection to a mathematical chair; his desire was to obtain the post of astronomer at tions and his profound that he might spend all his time upon his observations and his profound studies for the advancement of science.
Göttingen. ${ }^{2}$ His life was passed in a simple and regular manner, he enjoyed good sound health in spite of the fatigues of night observations, he seldom required a physician until a few months before his death, when he suffered much from asthma, which was subsequently complicated by the accession of dropsy. So passed away in his seventy-eighth year, Gauss, one of the greatest lights of the present age, a mathematician worthy to be placed on the same high platform as Archimedes and Newton.2

We are told that his tastes were simple (he never wore any of the numerous decorations which were showered down upon him); and that he had the full knowledge, which men of genius often have, of his superiority to the mass of mankind. ${ }^{3}$ Though he looked upon mathematics as the principal means for developing human knowledge, ${ }^{4}$ he yet fully recognised the beneficial influence of an acquaintance with classical literature. He had indeed a wonderful faculty for the acquisition of languages; he was acquainted with most of the European languages, and could speak many of them well. ${ }^{5}$ At the age of sixty-two he commenced the study of the Russian language, and mastered it in two years. He took a great. interest too in politics to within a few weeks of his death. His lectures, in which he adopted the analytic method, were exceedingly clear expositions ; in them he liked to discuss the methods and the roads by which he had arrived at his great results. He required the closest attention, and objected to the taking of notes, lest his hearers should lose the thread of his argument. The students seated round the lecture-table listened with delight to the lucid and animated addresses of their master; addresses more resembling conversations than set lectures. The chief figure in this group stands before us with clear, bright eyes, the right eyebrow raised higher than the left (more Astronomorum), a forehead high and wide, overhung with grey locks, and a coun. tenance whose variations were all expressive of the great mind within. ${ }^{6}$ We can well understand how his pupils reverenced him and never forgot these meetings. Gauss was always ready to converse even with persons unacquainted with the subjects he had made his own, and his animation in doing so bore evidence to the delight he took in the contemplation of nature. It was this feeling that led him a short time before his death to have engraved at the foot of his portrait the following lines as expressing best the philosophy of his ideas and of his writings :-

$$
\text { "Thou, Nature, art my Goddess, to thy laws }
$$$$
\text { My services are bound!" }
$$

“Gauss. Z. Ged.," p. 79. Shakspeare, King Lear, Act I. Scene ii.

The full list of Gauss's writings would fill many of our columns; there is a list on columns $854-857$ of Poggendorff; Larrouse gives a very full list also, but the most complete list we know, not including the larger works, is given in the Royal Society's Catalogue of Scientific Papers. The titles are given of 124 papers.

One of Gauss's earliest discoveries is the "method of least squares." This method, though first published by Legendre, was applied by Gauss as early as the year $1790^{7}$ It is some. what remarkable that Gauss has devoted so few memoirs to

${ }^{x} \mathrm{He}$ is said never to have slept from under the roof of his own observatory but on the one above-named occasion, and in the last-named year, i.e., the year before he died, to have seen for the first time a locomotive. " $\mathrm{During}$
this yisit to Berlin, Gauss made the acquaintance of Weber. "Z. Ged." p. $6 \mathrm{I}$.

${ }^{2}$ To use the words of Gauss's successor at Göttingen. A great living, English mathematician says: "The mathematician lives long and lives young: the wings of his soul do not early drop off, nor do its pores become clogged with the earthy particles blown from the dusty highways of vulgar life." (Dr. Sylvester's address at the Exeter Meeting of the British Association, r869.) He cites Leibnitz 70, Euler 76, Lagrange 77, Laplace 78 , Gauss
78 , Plato 82 , Newton 85, Archimedes 75 (then killed by a Roman soldier), ythagoras 99.

3 "Gauss. Z. Ged.," p. 95. He was a man of determined character, of strong will, and one who disdained all half-heartedness; (and p, to2) His character showed a curious mixture of self-conscious dignity and chidlike
simplicity. Larrouse says he was but little communicative and morose, not simplicity. Lay peevish.

4 A short time before his death he spoke to a celebrated psychologist on the 4 A short time before his death he spoke to a celebrated
possibility of putting psychology on a mathematical basis.

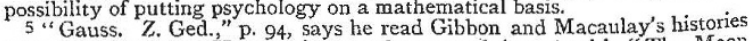
5 "Gauss. Z. Ged." p. 94, says he read Gibbon and Macaulay's histories
with great interest. He was immensely amused (p. 93) with "The Moon with great interest. He was immensely amused (p. 93 ) with "The Moon
rises broad in the north-west," which occurs in one of Sir W. Scott's novels. rises broad in the north-west," which occurs in one of Sir W. Scott's nove!s. He would not tell his friends what had set him laughing until after collecting a variety of editio

not a misprint. 6 We are here indebted to $M$. Wagener the writer of the notice in the 6 We are here indebted to $M$. Wagener the write
"Biographie Universelle (Michaud), "Paris, 1856 .

Biographie Universelle (Michaud), "Paris, $185^{36}$.
7 Theoria Motus, lib. it. \$ iii. See"Glaisher "On the Law of Facility of 7 Theoria Motus, lib. it. \$ iii. See Glaisher "On the Law of Facility of
Errors of Observations, and On the Method of Least Squares." Roy. Ast Errors of Observations, and On the Method of Least Squares." Roy. Ast Soc. Memoirs, vol. xxxix. ( 1872$)$, in which is collected much information on
the subject. Also Todhunter's "History of Theory of Probability," $\$$ I, OI7 the subject. Also Todhunter's "History of The
and elsewhere. Roy. Soc. Proceedings, p. 592. 
subjects of an algebraic character. If we except a comparatively unimportant paper on Descartes' Rule of Signs, which appeared in Crelle's Fournal (1828), his only algebraical memoirs relate to the theorem that every equation has a root. Of this he gave no less than three distinct demonstrations, one in 1799, one in 1815, and one in 1816 . That in 1799 formed the subject of his first published paper: "Demonstratio nova theorematis omnem functionem algebraicam, rationalem integram unius variabilis in factores reales primi vel secundi gradus resolvi posse"- his inaugural dissertation as a candidate for the degree of Doctor of Philosophy in the University of Göttingen. This demonstration was repeated over again in 1849 with certain changes and simplifications. These demonstrations are prior to any other $;^{1}$ for various reasons those subsequently given by Cauchy have been justly preferred for insertion in modern text-books.

A new epoch in certain branches of analysis dates from the publication of the "Disquisitiones Arithmeticæ"(Leipzig, I80I), and from the researches with which some years later Gauss supplemented or further developed the theories contained in that work. We must bear in mind that he found the theory of numbers as Euler and Lagrange had left it. The former enriched it with a multitude of results, relating to Diophantine problems, to the theory of the residues of powers, and to binary quadratic forms ; the latter had given the character of a general theory to some at least of these results by his discovery of the reduction of quadratic forms and of the true principles of the solution of in determinate equations of the second degree. Legendre (with many additions of his own) had endeavoured to arrange as much as possible of these scattered fragments of the science into a systematic whole in his "Essai sur la Théorie des Nombres." But the "D. Ar." was in the press when this important treatise appeared, and what in it was new to others was already known to Gauss. This grand work merits an analysis at our hands, but lack of space compels us to pass on at once to the fourth section. The greater portion of it is occupied with a research, which of itself alone would have placed Gauss in the first rank of mathematicians. "If $p$ and $q$ are positive uneven prime numbers, $p$ has the same quadratic character with regard to $q$ that $q$ has with regard to $p$; except when $p$ and $q$ are both of the form $4 n+3$, in which case the two characters are always opposite, instead of identical." This is the celebrated Fundamental Theorem of Gauss, known also as the Law of Quadratic Reciprocity of Legendre. Gauss discovered it (by induction) in March, I795, before he was eighteen; the proof given of it in this section he discovered in April of the year following. ${ }^{3} \mathrm{He}$ cannot at the earlier date have been aware that the theorem had been already enunciated (though in a somewhat complex form) by Euler, and that Legendre had attempted, though unsuccessfully, to prove it in the Memoirs of the Academy of Paris for I 784. The question of priority of enunciation or of demonstrating by induction in this case is a trifling one; any rigorous demonstration of it involved apparently insuperable difficulties. Gauss was not content with once vanquishing the difficulty, he returns to it again in the fifth section, and there obtains another demonstration reposing on entirely different, but perhaps still less elementary principles. In January, 1808 , he submitted a third demon. stration to the Royal Society of Göttingen; a fourth in August of the same year; a fifth and sixth in February, I8r . It is no wonder he should have felt a sort of personal attachment to a theorem which he had made so completely his own, and which he used to call the "gem" of the higher arithmetic. His six demonstrations remained for some time the only efforts in this direction, but the subject subsequently attracted the attention of other eminent mathematicians, and several proofs differing substantially from one another, and from those of Gauss, have been given. ${ }^{4}$. It would be impossible to exaggerate the important

x This dissertation (Helmstadt, I799), so little known that Lagrange appears not to have been acquainted with it, and "Cauchy has received in France all the praise due to a first discoverer."-Larrouse.

2 For an amusing notice of this work see "Biographie nouvelle des Contemporains" (Paris, I822) : "Cet ouvrage a obtenu un succès d'après lequel on serait tenté de croire que le charlatanisme envahit quelquefois jusqu'au domaine des mathématiques" (see Roy. Soc. Proceedings, pp. 590, 59r, ubi supra) Twelve years later ("Biographie universelle et portative des Contemporains, Paris, 1834) we read, "Il suffit de dire qu'en général ses travaux sont estimés des mathématiciens les plus distingués et qu'ils se recommandent autant par leur exactitude que par la clarté, la précision et l'élégance du style." Laplace's saying, quoted above, also shows in what estimation Gauss was held at that date. Lalande speaks of his talent and zeal, "Histoire," p. 813 $(1803)$

3 See Gauss's note (pp. 475,476 of vol. i. of his "Werke," edited by Schering).

${ }^{4}$ By Jacobi and Eisenstein in Germany, M. Liouville in France; perhaps the simplest of all (one allied in its character to the third proof of Gauss) is influence which this theorem has had on the subsequent development of arithmetic, and the discovery of its demonstration by Gauss must be certainly regarded (it was so regarded by himself), as one of his greatest scientific achievements. The fifth section ("these marvellous pages") abounds with subjects, each of which has been the starting-point of long series of important researches by subsequent mathematicians. In the Additamenta to this section Gauss characteristically adds : "ex voto nobis sic successit ut nihil amplius desiderandum supersit Nov, 30Dec. 3, I80o." It is remarkable that he should never have published the wonderful researches to which he here alludes. They first saw the light sixty-three years later in the second volume of the collected edition of his works. ${ }^{1}$ Till the time of Jacobi, it is not too much to say, that the profound researches of the fourth and fifth sections were passed over with almost universal neglect, but the seventh section at once made the reputation of the "D. Ar." The well-known theory of the division of the circle, comprised in this section, was received with great and deserved enthusiasm as a memorable addition to the theory of equations and to the geometry of the circle. Gauss's note on $\$ 365$ (" circulum in 17 partes divisibilem esse geometrice, deteximus 1796, Mart 30 ") $)^{2}$ is interesting because it shows that he was not yet nineteen when he made this great discovery. Even more remarkable; however, is a passage ( $\$ 335$ ), in which he observes that the principles of his method are applicable to

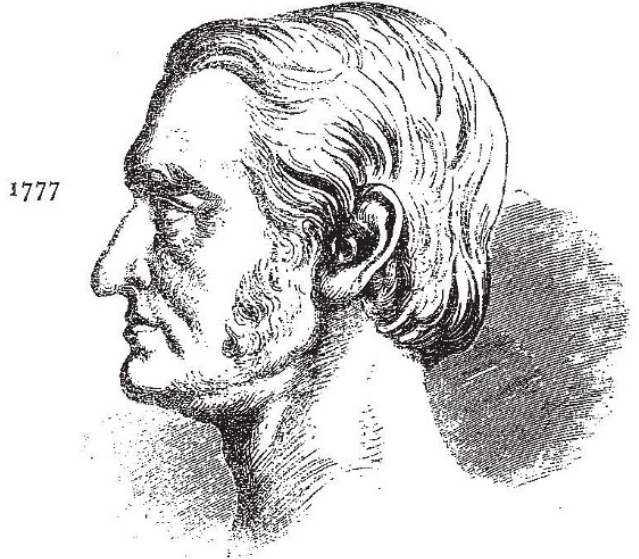

1877

Carl Friedrich Gauss.

many other functions beside the circular functions, and in particular to the transcendents dependent on the integral $\int \frac{d x}{\sqrt{x-x^{4}}}$ This almost casual remark shows (as Jacobi long since observed) that Gauss at the date of the publication of the "D. Ar." had already examined the nature and properties of the elliptic functions and had discovered their fundamental property, that of double periodicity. This observation of Jacobi's is amply confirmed by the papers on elliptic transcendents, now published in the third volume of Gauss's collected works. ${ }^{3}$

The "D. Ar." were to have included an eighth section ; at first it was intended to contain a complete theory of congruences, but subsequently Gauss appears to have proposed to continue the work by a more complete discussion of the theory of the division of the circle. Manuscript draits on each of these subjects were found among his papers; the first of them is especially interesting, as it treats of the general theory of congruences from a point of view closely allied to that subsequently taken by

one by M. Zeller (see Messenger of Mathematics, No. Ivii., January, I876 for an account by Prof. Paul Mansion).

fr an account by Prof. Paul Mansion). I The theorem to which they refer had, in the interval, been rediscovere and demonstrated by Lejeune Dirichlet. This demonstration has been to a certain extent simplified by $M$. Hermite, and the form of proof found in
Gauss's papers after his death approaches very nearly to that adopted by Gauss's papers

M. Hermite. out achering's edition, ubi supra. M. Chasles passes by not be the barrier out any notice of it ; in this case the language could not be the barrier, "Par suite de notre ignorance de la langue dans laquelle ils sont "Rapts. "Aperçu Historique," p. 2r5. Delambre gives an account in his "Rapport Historique sur les progres des Scienc

Notice are some pertinent remarks. 3 On p. 593 Roy. Soc. Obituary Notice will be found the story of Gauss and Jacobi. For every theorem in the subject of elliptic integrals produced by the latter, Gauss could show its fellow among his manuscripts. 
Evariste Galois and by MM. Serret and Dedekind. This draft appears to belong to the years 1797 and 1798 .

To complete our hasty sketch of the arithmetical works we need only mention ( $x$ ) the remarkable interpretation of the arithmetical theory of positive binary and ternary quadratic forms, which will be found in his review of the works of $L$. Seeber [1831] ("Werke," vol. ii. p. 188); and (2) the two important memoirs on the theory of biquadratic residues (1825 and 1831). In the second of these memoirs he gives a theorem of biquadratic reciprocity between any two prime numbers no less important than the quadratic law, viz., "If $p_{1}$ and $p_{2}$ are two primary prime numbers, the biquadratic character of $p_{3}$ with regard to $p_{2}$ is the same as that of $p_{2}$ with regard to $p_{1}$." This theorem itself and the introduction of imaginary integers upon which it depends, are memorable in the history of arithmetic for the number and variety of the researches to which they have given rise. ${ }^{1}$

A writer remarks each work of Gauss is an event in the history of science, a revolution, which, overturning the old theories and methods, replaces them by new ones and advances science to a height which no one had before dreamed of. ${ }^{2}$ We have given proof of this in one branch of mathematics; we shall see that the witness is true as to other branches also.

The discovery of the planet Ceres at Palermo on the first day of the present century led to Gauss's taking up the subject of astronomy. He did not come into possession of the requisite data until the October following. In a few weeks he determined the elements of its orbit with sufficient accuracy so that the Baron de Zach was enabled to rediscover the planet at the first attempt he made for that purpose on December 7 . This discovery was soon followed by that of three other small planets. These discoveries supplied Gauss with the means of further improving his solution of the problem, and in 1809 he brought out at Hamburg his "Theoria motus corporum cæles tium in sectionibus conicis solem ambientium." This contains an "elaborate discussion of the various problems which present themselves in the determination of the movements of planets and comets from observations made on them under any circum. stances." 1 Gauss's other astronomical researches are chiefly contained in De Zach's Monatlache Correspondenz, the Transactions of the Royal Society of Göttingen, and the Astronomische Nachrichten; all are contributions of the highest order of excellence.

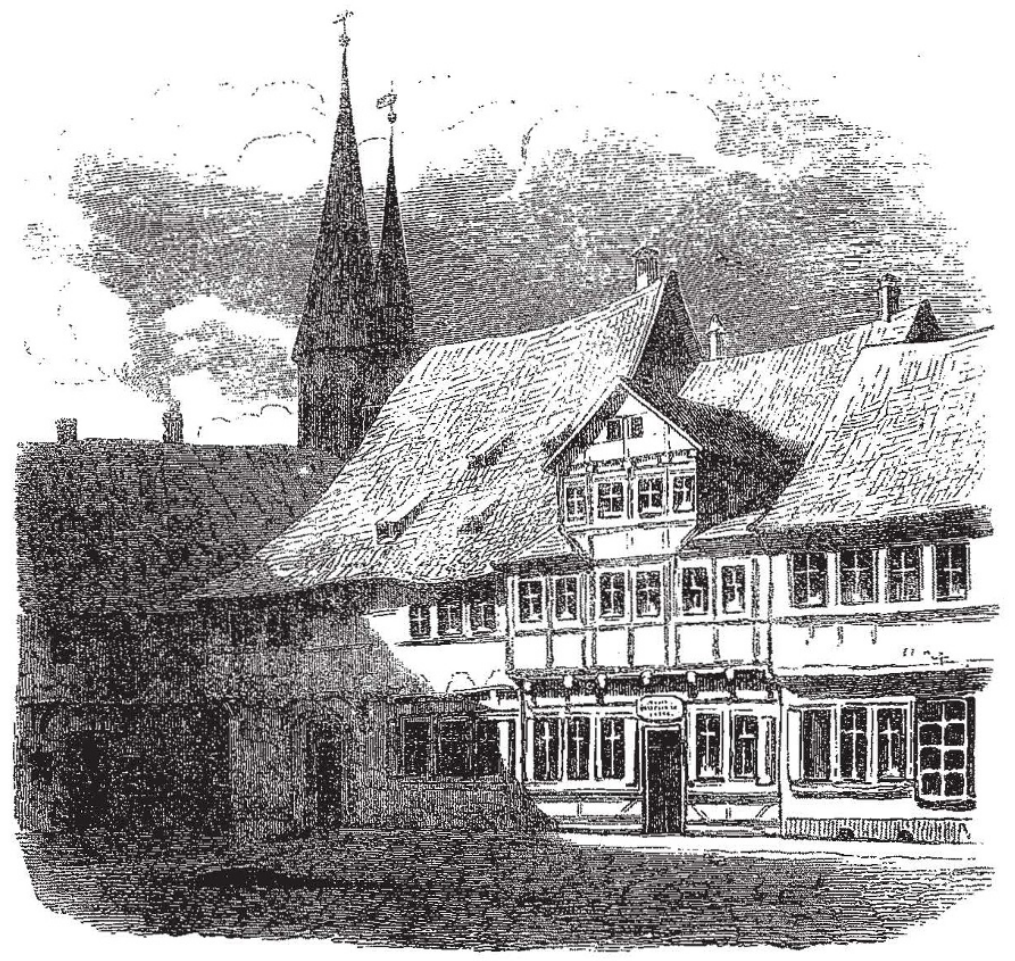

Gauss' Birthplace in Brunswick.

To astronomy Gauss joined geodesy, and the Hanoverian Government charged him with the triangulation and measurement of an arc of the meridian between Göttingen and Altona. This he accomplished between the years 1821 and 1824 . For carrying out his purpose he invented many methods quite original, ${ }^{3}$ It was his intention to publish an extensive work upon geodesy, but be did not accomplish his purpose. He contributed two memoirs on the subject to the Royal Society of Berlin (1844, I847).

¿ In our account of Gauss's arithmetical work we have throughout reely referred to Prof. H. J. S. Smith's presidential address (see above) and his two reports on the theory of numbers (Brit. Assoc. Reports, 1859 , pp. $228-267 ; 1860, p p .120-172)$. But we are still more deeply indebted to him for references and criticisms most kindly given in the midst of the pressing claims of his other numerous engagements.

" W Wagener, in Michaud's "Biographie Universelle." Prot. Cayley writes. "All that Gauss has written is first rate; the interesting thing would be to show the influence of his different memoirs in bringing to their present condition the subjects to which they relate, but this is to write a History of Mathematics from the year $x 800$.

${ }^{3} \mathrm{He}$ invented the heliotrope to render angles visible at as great a distance as possible; this he did by reflecting the rays of the sun. $\mathrm{He}$ also deyised a method for the correction of the errors which occur in an extensive system of triangulation.-" Gauss. Z. Ged.," pp. 5x*53*;
Mr. Todhunter in his " History of the Theories of Attraction," devotes $\$ 1162-1 \times 75$ to an analysis of a memoir by Gauss, "Theoria attractionis corporum sphæroidicorum ellipticorum homogeneorum methodo novâ tractata" (Royal Society of Göttin. gen, March 18, 1813). Mr. Todhunter says, "he completely succeeds in his design; his solution is both simple and elegant." He further remarks, "Gauss's writings are distinguished for the combination of mathematical ability with power of expression; in his hands Latin and German rival French itself for clearness and precision."

In another of Mr. Todhunter's works ("Calculus of Variations," I86I) he discusses in his third chapter (pp. 37.52) a memoir"

${ }^{\Sigma}$ Roy. Soc. Proceedings, p. 592 ; Roy. Ast. Soc. Monthly Notices (as above'. A curious fact is recorded. The preface to this work is dated March 28, r809, just two centuries after Kepler's "Præefatio de Stella Martis," March 28 1609; "Gauss. Z. Ged.," p. 40. After the publication of this work Gauss became "a member of all the learned societies from the Polar Circle to

2 Chasles (quoted by Todhunter) calls it "le beau mémoire de M. Gauss." Another celebrated memoir, "Allgemeine Lehrsätze... Anziehungs- und Abstossungs-kräfte ' (Leipsic, 1840 ), is treated by Todhunter, \& $x, 253$. In this last Gauss uses the name Potential (apparen
$\S 790$. See also Maxwell"s "Electricity," $\$ 70$. 
by Gauss entitled "Principia generalia Theoriæ figuræ Fluidorum in statu æquilibrii" (Royal Society of Göttingen, I833). It relates to the theory of capillary attraction, and demonstrates in a new way some results which had already been obtained by Laplace. The part analysed by Mr. Todhunter is that devoted to the solution of a problem in the calculus of variations, "involving the variation of a certain double integral, the limits of the integration being also variable; it is the earliest example of the solution of such a problem." In 1831 we find Gauss commencing the study of crystallography; in a few weeks he had mastered the subject. We find that the question of the rationality or irrationality of the ratios of the crystallographic coefficients had attracted his attention. ${ }^{2}$

We can only touch upon Gauss's further contributions to geometry. ${ }^{3}$ To him are due many fundamental theorems in the theory of curve-surfaces; also on the development of surfaces; thus it was he who found the equation to developable surfaces. He was used to say "that he had laid aside several questions which he had treated analytically, and hoped to apply to them geometrical methods in a future state of existence, when his conceptions of space should have become amplified and extended." 4

Those not acquainted with Gauss's writings would think we must have exhausted our account of them. In 1831 , however, on Weber's arrival at Göttingen, physical questions took the first place in Gauss's thoughts, and separately and in conjunction many works were brought out by these two philosophers. There is so full an account of Gauss's achievements in this direction in the Royal Society's Obituary Notice, that we need only refer to it. ${ }^{5} \quad$ His contributions, we may briefly say, to the knowledge of electro-magnetism and terrestrial magnetism were perhaps the most considerable and important of his achievements. He invented the magnetometer, and was one of the first to point out the possibility of sending signals by galvanic currents, and so contributed to the invention of the electric telegraph.

6 "If we except the great name of Newton (and the exception is one which Gauss himself would have been delighted to make) it is probable that no mathematician of any age or country has ever surpassed Gauss in the combination of an abundant fertility of invention with an absolute rigorousness in demonstration, which the ancient Greeks themselves might have envied. It may be admitted, without any disparagement to the eminence of such great mathematicians as Euler and Cauchy that they were so overwhelmed with the exuberant wealth of their own creations, and so fascinated by the interest attaching to the results at which they arrived, that they did not greatly care to expend their time in arranging their ideas in a strictly logical order, or even in establishing by irrefragable proof propositions which they instinctively felt, and could almosi see to be true. With Gauss the case was otherwise. . . . It may seem paradoxical, but it is probably nevertheless true that it is precisely the effort after a logical perfection of form which has rendered the writings of Gauss open to the charge of obscurity and unnecessary difficuity. The fact is that there is neither obscurity nor difficulty in his writings, as long as we read them in the submissive spirit in which an intelligent schoolboy is made to read his Euclid.

\section{Read Sept. 28, 1829}

'See Gauss's review of Seeber's Untersuchungen über die Eigenschaften der positiven ternären quadratischen formen" in the Göttingen gelehrte Anzeigen ( $183 \mathrm{x}$ ) or Crelle, vol. xx. p. 312. Prof. H. J. S. Smith "On the Conditions of Perpendicularity in a Parallelopipedal System." (London Math. Society's Proceedings, December, 1876 ). His method of drawing the crystals was essentially the same as that devised subsequently by Prof, Miller, of Cambrigge. "Gauss. Z. Ged.. p. 6r.

3 Disquisitiones generales circasuperficies curvas(Transactions, Göttingen, 1827 ).

2. Ged., p. 81, quoted by Prof Sylvester (ubi supra). Gauss's connection with the so-called Gaussian logarithms is pointed out on p. 75 of
the Report of the Committee on Mathematical Tables (Brit. Assoc., I873.)

the Report of the Committee on
Reporter, Mr. J. W. L. Glaisher.

5 "Gauss, as a member of the German Magnetic Union, brought his powerful intellect to bear on the theory of magnetism and on the methods of observing it, and lie not only added greatly to our knowledge of the theory of attractions, but reconstructed the whole of magnetic science as regards the instruments used, the methods of observation, and the calculation of the results, so that his memoirs on Terrestrial Magnetism may be taken as models of physical research by all those who are engaged in the measurement of any of the forces in nature."-Prof. Clerk-Maxwell's "Electricity and Magnetism " ( 1873 ), p. viii. We may also refer for a statement of some of Gauss's discoveries to $\$ \S x 4^{\circ}, 144,409,421,454,706$, and $744 . C f$. also Prof. Maxwell's Address (Brit. Assoc, Liverpoul, 1870). Pp. 594-598 for accounts of the memoir "Intensitas vis magnetica terrestris ad mensuram (1839): "Aligemeine 'Theorie des Erdmagnetismus.

6 We quote freely from notes placed at our service for this article by Prof. H. J. S. Smith. "Summus Newton," "Gauss. Z. Ged.," p. 84.
Every assertion that is made is fully proved, and the assertions succeed one another in a perfectly just analogical order; there is nothing so far of which we can complain. But when we have finished the perusal, we soon begin to feel that our work is but begun, that we are still standing on the threshold of the temple, and that there is a secret which lies behind the veil and is as yet concealed from us . . . . no vestige appears of the process by which the result itself was obtained, perhaps not even a trace of the considerations which suggested the successive steps of the demonstration. Gauss says more than once that, for brevity, he only gives the synthesis, and suppresses the analysis of his propositions. 'Pauca sed matura' were the words with which he delighted to describe the character which he endeavoured to impress upon his mathematical writings. . . . . If, on the other hand, we turn to a memoir of Euler's, there is a sort of free and luxuriant gracefulness about the whole performance, which tells of the quiet pleasure which Euler must have taken in each step of his work ; but we are conscious nevertheless that we are at an immense distance from the severe grandeur of design which is characteristic of all Gauss's greater efforts. The preceding criticism, if just, ought not to appear wholly trivial ; for though it is quite true that in any mathematical work the substance is immeasurably more important than the form, yet it cannot be doubted that many mathematical memoirs of our own time suffer greatly (if we may dare to say so) from a certain slovenliness in the mode of presentation; and that (whatever may be the value of their contents) they are stamped with a character of slightness and perishableness, which contrasts strongly with the adamantine solidity and clear hard modelling, which (we may be sure) will keep the writings of Gauss from being forgotten long after the chief results and methods contained in them have been incorporated in trea. tises more easily read, and have come to form a part of the common patrimony of all working mathematicians. And we must never forget (what in an age so fertile of new mathematical conceptions as our own, we are only too apt to forget), that it is the business of mathematical science not only to discover new truths and new methods, but also to establish them, at whatever cost of time and labour, upon a basis of irrefragable reasoning.

"The $\mu a \theta \eta \mu \alpha \tau \iota k \dot{s} s \pi i \theta \alpha \nu \lambda o \gamma \hat{\omega} \nu$ has no more right to be listened to now than he had in the days of Aristotle; but it must be owned that since the invention of the 'royal roads' of analysis, defective modes of reasoning and of proof have had a chance of obtaining currency which they never had before. It is not the greatest, but it is perhaps not the least, of Gauss's claims to the admiration of mathematicians, that, while fully penetrated with a sense of the vastness of the science, he exacted the utmost rigorousness in every part of it, never passed over a difficulty, as if it did not exist, and never accepted a theorem as true beyond the limits within which it could actually be demonstrated."

It will be evident to our readers that this notice has been drawn up with a purpose. 'The town of Brunswick proposes to celebrate the hundredth anniversary of Gauss's birthday, ard the committee hope to have received before the $3^{\text {th }}$ instant, sufficient subscriptions to enable them to lay the foundation stone of a memorial statue. We have endeavoured to present in a strong light ${ }^{1}$ the claims which this great mathematician has upon mathematicians, not only in Germany, but on mathematicians in this country.

Gauss might himself have considered his works his best monument ("exegi monumentum aere perennius,") and possibly if sufficient funds flow in, the committee might see their way to the bringing out a centenary edition of them. In this way they would confer a great boon upon mathematicians every where, for at present his writings are, as our great mathematical historian writes, "very costly."

R. TUCKER

x Our task has given us much pleasure; it has been accomplished in the midst of many interruptions. All our authorities have been given. We close, as the author of the Book of Maccabees closes, with saying: "If Thave done well and as is fitting the story, it is that which " desired; but if slenderly and meanly, it is thac which could attain unto.

a ' be sent to the office of NATURE up to the 26 th instant. Sein Tod wird nicht allein in allen deutschen Landen sondern auch Gelellerte Anzeigen, No. 16, December 3, 1855 .

Gclellurte Anzeigen, No. 16, December 3,1855 . 3 Carl Friedrich Gauss Werke, Herausgegeben von der königliche Gesellschaft der Wissenschaften zu Göttingen: vol. i. it. 1863, vol. i1. I866, vol. iv. 1873 , vol. v. 1867 , vol, vi. 1874 , vol. vii, 1871 . These are all we have seen. The editor is Schering. The house in which Gauss was born bore the number 1550 , and was situated on the west side of the Wendengraben. It now has a memorial tablet. The house was sold in 1804 , and church. "Z. Ged.,"p. 8. 